\title{
TINGKAT BURNOUT CAREGIVER KLIEN SKIZOFRENIA DI DESA KERSAMANAH KABUPATEN GARUT
}

\section{Burnout Level Caregiver Clients Schizofrenia in Villages Kersamanah District Garut}

\author{
Yulianti $^{1}$, Aulia Iskandarsyah ${ }^{2}$, Imas Rafiyah $^{3}$ \\ ${ }^{1}$ Akper Pelni Jakarta; ${ }^{2}$ Fakultas Psikologi, Universitas Padjadjaran; \\ ${ }^{3}$ Fakultas Keperawatan, Universitas Padjadjaran \\ Email: yulianti.ners@gmail.com, auliaiskandarsyah@yahoo.com, \\ imasrafiyah@fkep.unpad.ac.id
}

\begin{abstract}
Abstrak
Prevalensi burnout pada caregiver skizofrenia menunjukkan angka yang cukup tinggi dibandingkan dengan penyakit kronis lainnya. Burnout merupakan ketegangan psikologis yang secara spesifik berkaitan dengan stres kronis yang dialami individu dari hari ke hari dan ditandai dengan keadaan kelelahan fisik, mental, dan emosional kondisi ini dapat menyebabkan caregiver mengalami depresi atau gangguan jiwa. Tujuan dari penelitian ini adalah untuk mengetahui tingkat burnout caregiver klien skizofrenia. Penelitian ini merupakan penelitian deskriptif yang dilaksanakan di Desa Kersamanah Kabupaten Garut. Tingkat burnout caregiver diukur dengan menggunakan Maslach Burnout Inventory-Human Services Survey (MBI-HSS). Hasil penelitian menunjukkan bahwa tingkat burnout caregiver klien skizofrenia menunjukkan hasil sebagian besar caregiver berada pada tingkat burnout yang tinggi (63\%). Hasil penelitian ini diharapkan dapat menambah ilmu dan terapi keperawatan jiwa khususnya untuk mengatasai masalah psikososial terutama burnout yang terjadi pada caregiver skizofrenia.
\end{abstract}

Kata kunci : burnout, caregiver, skizofrenia

\begin{abstract}
The prevalence of burnout in caregiver clients schizophrenia shows a fairly high rate compared with other chronic diseases. Burnout is a psychological tension that is specifically related to chronic stress experienced by individuals from day to day and is characterized by a state of physical, mental, and emotional exhaustion. This condition can cause the caregiver to experience depression or mental disorder. The purpose of this research is to indicate the burnout caregiver level of schizophrenia clients. This research is a descriptive research conducted in the Village Kersamanah, Garut Regency. The caregiver burnout rate is measured using Maslach Burnout Inventory-Human Services Survey (MBI-HSS). The results show that the burnout caregiver level of schizophrenic clients most of caregiver were at high burnout rate-sixty three percent $(63 \%)$. The results of this study are expected to shade a light of knowledge in the mental treatment nursing, especially to overcome psychosocial problems, particularly in burnout that occurs in caregiver schizophrenia.
\end{abstract}

Keywords: burnout, caregiver, schizophrenia

\section{PENDAHULUAN}

Peningkatan prevalensi gangguan jiwa terjadi secara global. World Health Organization [WHO] (2009) memperkirakan sebanyak 450 juta orang di seluruh dunia mengalami gangguan jiwa. Gangguan jiwa mencapai $13 \%$ dari penyakit secara keseluruhan dan kemungkinan akan berkembang menjadi
25\% di tahun 2030. Berdasarkan Riset Kesehatan Dasar (Riskesdas) tahun 2007, prevalensi gangguan jiwa mencapai $0,46 \%$ dari jumlah total penduduk Indonesia atau sekitar 1.065.000 orang. Dalam Riskesdas tahun 2013 prevalensi gangguan jiwa pada penduduk Indonesia 1,7 per mil atau 1-2 orang dari 1000 penduduk Indonesia mengalami gangguan jiwa dari 250 juta 
penduduk, di Jawa Barat sendiri mencapai 72.000 dari 45,5 juta penduduk. Sedangkan jumlah penduduk Garut yang mengalami gangguan jiwa sekitar 4.805 orang dari total penduduk 3.003.004 jiwa. Begitupun prevalensi gangguan jiwa yang ada di Kersamanah Garut berdasarkan data di puskesmas Kersamanah menunjukkan bahwa data tahun 2012 terdapat 98 klien skizofrenia dan pada tahun 2014 menjadi 125 penderita, desa ini juga sempat diberitakan sebagai "desa gila" pada tahun 2008 dalam salah satu media massa di Jawa Barat.

Skizofrenia termasuk jenis gangguan jiwa yang menempati urutan atas dari jenis psikosis yang ada (Rubbyana, 2012). Psikosis adalah kondisi mental dimana terjadi disorganisasi kepribadian, kerusakan dalam fungsi sosial, dan kehilangan kontak atau distorsi terhadap realita. Pada kondisi ini klien tidak akan menyadari bahwa orang lain tidak mengalami apa yang dialaminya dan klien akan merasa heran karena orang lain tidak bereaksi sama dengan dirinya (Stuart, 2013). Skizofrenia dianggap juga sebagai penyakit yang tidak kalah bahaya dibandingkan dengan penyakit fisik kronis lainnya.

Skizofrenia merupakan suatu gangguan jiwa yang ditandai dengan adanya hendaya nyata pada taraf kemampuan fungsional sebelumnya yang dapat terlibat dalam bidang pekerjaan, hubungan sosial, dan kemampuan merawat diri sendiri (Bentsen, 2001; Lefley, 2001; Kaplan \& Sadock, 2007), sehingga memerlukan bantuan dan pertolongan dalam memenuhi kebutuhan hidupnya pada orang lain terhadap dirinya (caregiver) (National Institute of Mental Health [NIMH], 2012). Hal ini sejalan dengan apa yang disampaikan oleh Rubin dan Peyrot (2002) dalam penelitiannya bahwa $77 \%$ klien dengan penyakit kronis merasa membutuhkan pertolongan keluarganya sebagai caregiver.

Menjalankan peran sebagai caregiver dihadapkan dengan berbagai tuntutan dan tugas-tugas merawat klien ataupun tugas sebagai seorang individu. Tuntutan tersebut dapat menjadi sumber konflik yang dapat menimbulkan ketegangan dan tekanan yang dapat menimbulkan perasaan cemas, stres, frustrasi, kelelahan psikis bahkan depresi bagi caregiver (Yusuf, Nuhu \& Akinbiyi, 2009). Ketegangan dan keputusasaan dalam keluarga berlangsung tidak hanya sementara (Freadman, Bowden, \& Jones, 2003). Kondisi-kondisi ini menempatkan caregiver mengalami burden.

Respon setiap caregiver dalam menghadapi burden berbeda-beda. Perbedaan ini dipengaruhi oleh ciri-ciri psikologis yang terdapat dalam diri caregiver tersebut. Hasil penelitian (Schultz, 2000; Teasell et.al., 2011; Brown, Brown \& Penner, 2012), menjelaskan perbedaan persepsi caregiver terhadap pemaknaan dan pemahaman tentang gangguan skizofrenia yang merupakan kemampuan coping dan penerimaan atau anggapan terhadap perawatan itu sendiri (Maldonado, Urizar, \& Kavanagh, 2005). Sedangkan tingkat stres, kemampuan coping dan penerimaan sesorang dipengaruhi oleh kepribadian orang tersebut.

Jika seorang caregiver memiliki kemampuan yang rendah dalam mengendalikan emosi yang merupakan salah satu karakteristik kepribadian, maka akan menambah masalah yang berdampak bagi klien dan diri caregiver itu sendiri. Maslach dan Leiter (1988) menyatakan bahwa seseorang ketika melayani klien pada umumnya mengalami emosi negatif, misalnya marah, jengkel, takut, cemas, dan khawatir. Bila emosi-emosi tersebut tidak dapat dikuasai, mereka akan bersikap impulsif, menggunakan mekanisme pertahanan diri secara berlebihan atau menjadi terlarut dalam permasalahan klien. Kondisi tersebut akan memicu timbulnya burnout pada caregiver.

Burnout merupakan ketegangan psikologis yang secara spesifik berkaitan dengan stres kronis yang dialami individu dari hari ke hari dan ditandai dengan keadaan kelelahan fisik, mental, dan emosional (Etzion, 1984 sebagaimana dikutip dalam Lailani, 2012). Menurut National Alliance on Mental Illness [NAMI] (2008), caregiver sering merasa terisolasi, kesepian, cemas dan burned out. Maslach, Schaufeli, dan Leiter (2001) 
membagi burnout kedalam tiga dimensi yaitu: sindrom kelelahan emosional (emotional exhaustion), depersonalisasi (depersonalization), dan rendahnya penghargaan terhadap kemampuan diri sendiri (low personal accomplishment).

Prevalensi burnout pada caregiver skizofrenia menunjukkan angka yang cukup tinggi dibandingkan dengan penyakit kronis lainnya. Hal ini sesuai dengan penelitian yang dilakukan oleh Kokurcan, Yilmaz, dan Göğüş (2014) tentang burnout in caregiver of patients with schizophrenia dengan membandingkan tingkat burnout yang dialami oleh caregiver skizofrenia dengan caregiver penyakit kronis lainnya, hasil penelitiannya menunjukkan bahwa tingkat burnout pada caregiver skizofrenia lebih tinggi dibandingkan dengan tingkat burnout pada caregiver penyakit kronis lainnya.

Studi pendahuluan yang dilakukan pada saat peneliti melakukan praktek residensi di desa Kersamanah Garut pada tanggal 2-16 Desember 2014 dengan melakukan binaan pada 20 keluarga, didapatkan data bahwa 16 keluarga mengatakan sudah lelah merawat klien karena sudah banyak biaya dan waktu yang diluangkan untuk mencari pengobatan. Terdapat satu keluarga yang membiarkan klien dengan menempatkan klien di dekat kandang kambing dengan kondisi yang sangat tidak layak, dan dua keluarga melakukan pasung, keluarga melakukan hal tersebut dikarenakan sudah tidak tahu harus melakukan apa dan merasa lelah merawat klien karena sudah bertahun-tahun kondisinya tidak membaik. Selain itu, 12 keluarga mengungkapkan bahwa merasa sudah tidak ada harapan lagi, dan 8 keluarga merasa kebingungan dan putus asa akan masa depan klien, ini terutama dirasakan oleh keluarga dengan klien usia produktif.

\section{METODE PENELITIAN}

Penelitian ini merupakan penelitian deskriptif yang dilaksanakan pada $2 \mathrm{Mei}-$ 13 Juni 2015 di Desa Kersamanah Kabupaten Garut. Kriteria inklusi dalam penelitian ini adalah 1) keluarga sebagai caregiver primer klien skizofrenia; 2) bisa baca tulis; 3) caregiver yang mengalami burnout sedang dan berat; 4) telah menjadi caregiver klien skizofrenia minimal 6 bulan; dan 5) caregiver tinggal satu rumah dengan klien skizofrenia Adapun kriteria eksklusi yang peneliti tetapkan adalah caregiver dalam kondisi sakit dengan memerlukan perawatan lebih lanjut (perawatan di rumah sakit atau istirahat total dirumah) saat intervensi berlangsung, dan klien skizofrenia mengalami kekambuhan sehingga caregiver harus merawat dan membawa klien ke rumah sakit. Dari hasil pengambilan data yang sesuai dengan kriteria inklusi dan eksklusi didapatkan responden sebanyak 32 orang.

Pengukuran burnout caregiver dalam penelitian ini menggunakan Maslach Burnout Inventor-Human Services Survey (MBI-HSS).

Tabel 1. Sebaran item MBI-HSS

\begin{tabular}{lc}
\hline \multicolumn{1}{c}{ Aspek Burnout } & Nomor Item \\
\hline $\begin{array}{l}\text { Kelelahan } \\
\text { emosional }\end{array}$ & $1,2,3,6,8,13,14,16,20$ \\
$\begin{array}{l}\text { Depersonalisasi } \\
\begin{array}{l}\text { Penurunan hasrat } \\
\text { pencapaian diri }\end{array}\end{array}$ & $5,10,11,15,22$ \\
\hline
\end{tabular}

Kuesioner ini menggunakan jawaban berbentuk skala Likert (0-6) yang merupakan alat pengumpul data berupa daftar pertanyaan tertutup dengan bentuk jawaban tidak pernah, beberapa kali dalam setahun, sekali dalam sebulan, beberapa kali dalam sebulan, sekali dalam seminggu, dan setiap hari. Item-item gejala kelelahan emosional dan depersonalisasi bersifat negatif, sehingga semakin tinggi jumlah angka menunjukkan kondisi burnout yang semakin parah. Sedangkan item penurunan hasrat pencapaian diri bersifat positif, sehingga semakin tinggi jumlah angka yang diperoleh menunjukkan kondisi burnout yang ringan. Dari hasil penjumlahan setiap gejala diketahui derajat masing-masing gejala dalam kategori rendah, sedang, dan tinggi.

\section{HASIL PENELITIAN}

Skor tingkat burnout caregiver berdasarkan emotional exhaustion (EE), depersonalization (DP), dan low personal 
accomplishment (PP) klien skizofrenia tertuang dalam table dibawah ini:

Tabel 2. Tingkat burnout caregiver klien Skizofrenia

\begin{tabular}{|c|c|c|c|c|c|c|c|c|}
\hline \multicolumn{9}{|c|}{ klien Skizofrenia } \\
\hline & \multicolumn{2}{|c|}{$\mathrm{EE}$} & \multicolumn{2}{|c|}{ DP } & \multicolumn{2}{|c|}{ PP } & \multicolumn{2}{|c|}{$\begin{array}{c}\text { Burn } \\
\text { out }\end{array}$} \\
\hline & $\sum$ & $\%$ & $\sum$ & $\%$ & $\sum$ & $\%$ & $\sum$ & $\%$ \\
\hline \multirow{2}{*}{ Tinggi } & 1 & 5 & 2 & 7 & & & & 6 \\
\hline & 9 & 9 & 4 & 5 & 0 & 0 & 20 & 3 \\
\hline \multirow{2}{*}{ Sedang } & 1 & 4 & & 2 & 1 & 3 & & 3 \\
\hline & 3 & 1 & 8 & 5 & 2 & 8 & 12 & 8 \\
\hline \multirow[t]{2}{*}{ Rendah } & & & & & 2 & 6 & & \\
\hline & 0 & 0 & 0 & 0 & 0 & 3 & 0 & 0 \\
\hline
\end{tabular}

Dari data pada tabel menunjukkan data bahwa sebagian besar (59\%) skor EE berada pada tingkat yang tinggi, hampir seluruh caregiver (75\%) skor DP berapa pada tingkat tinggi dan skor PP berada pada tingkat rendah pada sebagian besar caregiver $(63 \%)$. Sehingga dapat dilihat bahwa tingkat burnout caregiver klien skizofrenia menunjukkan hasil sebagian besar caregiver berada pada tingkat burnout yang tinggi (63\%).

\section{PEMBAHASAN}

Hasil analisa tingkat burnout caregiver sebelum dilakukan intervensi pada kelompok kontrol dan kelompok intervensi, menunjukkan sebagian besar tingkat burnout caregiver yang tinggi dengan angka $62.5 \%$. Hal ini menunjukkan bahwa caregiver klien skizofrenia memiliki tingkat burnout yang tinggi. Penelitian yang mendukung adalah penelitian yang dilakukan oleh Onwumere, et al (2015) bahwa tingkat burnout caregiver gangguan jiwa sebesar $78 \%$ mengalami burnout tingkat tinggi dengan 7\% memenuhi kriteria penuh untuk burnout tinggi disemua dimensi burnout.

Tingginya skor burnout caregiver ini disebabkan karena caregiver sebagai responden dalam penelitian ini telah merawat klien minimal selama enam bulan. Kondisi ini dapat menyebabkan meningkatnya stres emosional dan ekonomi caregiver. Hal ini sesuai dengan penelitian yang menunjukkan bahwa tingkat stres caregiver meningkat karena masalah keuangan keluarga (Caqueo-Uríza et al., 2014). Fontaine (2009) menyatakan bahwa beban caregiver adalah tingkat pengalaman distress caregiver sebagai efek dari kondisi anggota keluarganya. Penelitian lain yang dilakukan oleh Yusuf et al. (2009) didapatkan bahwa caregiver memiliki beban yang besar dalam merawat klien skizofrenia jika dikaitkan dengan faktor keuangan, stigma dan perilaku klien yang negatif. Beban pada diri caregiver membawa konsekuensi negatif terhadap keadaan fisik, keadaan emosi, serta keadaan ekonomi. Tingkat stres yang berhubungan dengan beban caregiver dalam merawat klien skizofrenia dapat membuat caregiver rentan terhadap burnout (Truzzi, et al., 2012).

Maslach (1982) menjelaskan bahwa burnout merupakan respon terhadap situasi yang menuntut secara emosional dengan adanya tuntutan dari menerima pengasuhan yang memerlukan bantuan, pertolongan, dan perhatian dari pemberi pengasuhan. Hal serupa dikemukakan oleh Baron, et al. (1994) bahwa burnout merupakan kondisi kelelahan fisik dan psikologis terhadap stres kronis akibat keterlibatan dengan orang lain yang membutuhkan. Dalam DSM-V (Diagnostic and Statistic Manual of Mental Disorder) burnout juga didefinisikan sebagai gangguan penyesuaian jiwa yang ditandai dengan perkembangan gejala emosional atau perilaku yang signifikan secara klinis dalam menanggapi stressor psikososial atau stres. Burnout bukan merupakan reaksi langsung dari stressor, tapi akibat dari stres kronis yang berlangsung agak lambat dan tidak selesai setelah enam bulan.

Caregiver yang mengalami burnout erat dengan terganggunya kondisi psikologisnya, sehingga dapat menyebabkan caregiver mengalami masalah psikososial. Perawat jiwa adalah salah satu profesi yang ikut bertanggung jawab terhadap penanganan masalah psikologis yang dialami caregiver, agar ke depan hal ini tidak menjadi penyebab gangguan kejiwaan. Penanganan secara dini inilah yang dapat dilakukan untuk mengantisipasi terjadinya gangguan jiwa terkait peran caregiver yang dijalankan oleh keluarga dalam merawat klien skizofrenia. 


\section{SIMPULAN}

Tingkat burnout caregiver klien skizofrenia menunjukkan hasil sebagian besar caregiver berada pada tingkat burnout yang tinggi (63\%).

\section{SARAN}

Hasil penelitian ini diharapkan dapat menambah ilmu dan terapi keperawatan jiwa khususnya untuk mengatasai masalah psikososial terutama burnout yang terjadi pada caregiver skizofrenia.

\section{DAFTAR PUSTAKA}

Baron, R.A., \& Byrne, D. 1994. Social Psychology Understanding Human Interaction. Boston: Allyn and Bacon Inc.

Bentsen, H. 2001. Relatives distress and patients symptomps and behaviors: a prospective study of patients with schizophrenia and their relatives. Acta Psychiatrica Scandinavia : 104 (1): 42-50

Brown, S.L., Brown, R. M, \& Penner, L. A. 2012. Moving beyond selfinterest: Perspectives from evolutionary biology, neuroscience, and the social sciences. New York: Oxford University Press, Inc

Caqueo, U.A., Miranda, C.C., Giráldez, S.L., Maturana, S.L., Pérez, M.R., \& Tapia, F.M. 2014. An updated review on burden on caregivers of schizophrenia patients. Psicothema, Vol. 26, No. 2, 235243

Departemen Kesehatan RI. 2013. Riset kesehatan dasar 2013. Jakarta. Badan Penelitian dan Pengembangan Kesehatan Republik Indonesia.

Eztion, Dalia. 1984. Moderting Effect Of Social Support On The Stress Burnout Relationship. Journal of Applied Psychology, VOL 69 (4), NOV 1984, 615-622

Fontaine, K.L. 2009. Mental health nursing sixth edition. New Jersey: Pearson Prentice Inc

Freadman, Bowden, \& Jones. 2003. Family nursing: Research, theory and practice, 5th edition, New Jersey : Pearson Education, Inc.

Kaplan, B.J., \& Sadock, V.A. 2007. Schizophrenia. dalam Kaplan dan Sadock: Synopsis of psychiatry. Edisi ke 10 USA: Williams \& Wilkins

Kokurcan, Ahmet, Yilmaz Özpolat, \& Göğüş, Ali Kemal. 2014. Burnout in caregiver of patients with schizophrenia. Department of Psychiatry, Faculty of Medicine, Ankara University, Ankara, Turkey.

Lailani, Ferishti. 2012. Burnout pada perawat ditinjau dari efikasi diri dan dukungan sosial. Jurnal Talenta Psikologi Vo. 1 No. 1.

Lefley, H.P. 2000. The impact of mental disorder on family and carers. Dalam Thornicroft, Szmukler $(E d$.$) : Textbook of community$ psychiatry. USA: Oxford University Press.

Maldonado JG, Urizar AC, Kavanagh DJ. 2005. Burden of care and general in families of patients with schizophrenia. Social Psychiatry and Psychiatric Epidemiology; 40:899-904.

National institude of Mental Health (NIMH). 2012. Schizophrenia. www.nimh.nih.gov. Diakses pada tangal 27 Februari 2015.

Onwumere, Lotey, Schulz, James, Afsharzadegan, Harvey, Chu Man, Kuipers, \& Raune. 2015. Burnout in early course psychosis caregivers: the role of illness beliefs and coping styles. Early Intervention in psychiatry. Doi:10.1111/eip.12227

Rubin, R. R., \& Peyrot, M. 2002. Psychological Issue \& Treatments for people with Diabetes. Journal of Clinical Psychology, 57(4).

Schulz, R. 2000. Handbook on dementia caregiving: evidence-based intervention for family caregivers. New York: SpringerPublishing Company, Inc

Truzzi, A., Valente, L., Ulstein, I., Engelhardt, E., Laks, J., \& Engedal,. K. 2012. Burnout in 
familial caregivers of patients with dementia. Journal of the Brazilian Psychiatric Association. Elsevier Editora Ltda. All rights reserved.

World Health Organization (WHO). 2009.

Improving health system and service and service for mental health : WHO Library Cataloguing-in-Publication Data.

Yusuf, A.J., Nuhu, F. T., \& Akinbiyi, A. 2009. Caregiver burden among relatives of patient with skizofrenia in Katsina, Nigeria. South African Jurnal of Psychiatry, Vol. 15 No. 2. 